\title{
THE RIEDER AUTOMATIC RIFLE ATTACHMENT
}

\section{LT CDR W. M. BISSET*}

In March 1981, Mrs H. J. R. Rieder donated her husband's presentation British .303 SMLE Rifle No 1 Mark III (number M-45374) with the Rieder Automatic Rifle Attachment to the Military Museum at the Castle in Cape Town. With it were a number of photographs, letters, documents and plans concerning this once secret invention which was tested outside the Castle during the Second World War. Fortunately, the documents donated by Mrs Rieder include a list of the numbers of the 18 rifles to which Mr Rieder's automatic attachment was fitted and it is hoped that the publication of this information will lead to the discovery of some of them and be of considerable interest to their present owners.

France surrendered on 17 June 1940 and to many a swift German victory seemed inevitable. In July 1940, Mr H. J. R. Rieder discussed the simple conversion of a standard .303 rifle to a full automatic rifle with Lt Col M. E. Ross, the Staff Officer A11 at Cape Command Headquarters in the Castle. ${ }^{1} \mathrm{Mr}$ Rieder, a radio and television experimenter and inventor, was employed in the Mechanician Department of the General Post Office in Cape Town. Although of German ancestry he had served in the Royal Corps of Signals during the First World War. ${ }^{2}$

On 22 July $1940 \mathrm{Mr}$ Rieder wrote to the Officer Commanding Cape Command requesting the loan of 'one standard service rifle for minor alterations and fitting of conversion unit for demonstration purposes only'. Mr Rieder added that the normal operation of the rifle would not be impaired and that an old used rifle would be quite adequate.

In a reply dated 3 August 1940 a LieutenantColonel wrote on behalf of the Director-General of Technical Services that Mr Rieder should be asked 'to explain the principle which he proposed to adopt and submit drawings or sketches of his design'. The writer doubted whether an automatic rifle was of much value, since none had been adopted to any great extent by any of the powers. $\mathrm{He}$ added that the ammunition supply was one difficulty.

On 23 September 1940 the Deputy Director of Coast Artillery, Lt Col H. E. Cilliers, authorised Mr
Rieder to 'hold in his possession one rifle Mk 111 No 45374' for experimental purposes, but on 18 November 1940 he wrote that the Senior Stores Officer was 'pressing for its return' and requested a progress report.

Mr Rieder manufactured his automatic rifle attachment in his home, Windyways, 37, Upper Glengariff Road, Three Anchor Bay and was supplied with blanks with which to test it. A kingsize silencer deadened the noise which would otherwise have aroused the suspicions of the neighbours. ${ }^{3} \mathrm{Mr} \mathrm{P}$. D. Rieder, the youngest son of the inventor, recalls that his father was later granted a temporary transfer to the UDF and wore army uniform. All subsequent work on the invention took place in an upstairs workshop in the Castle and a sergeant was assigned the task of assisting $\mathrm{Mr}$ Rieder. ${ }^{4} \mathrm{~A}$ detailed description of

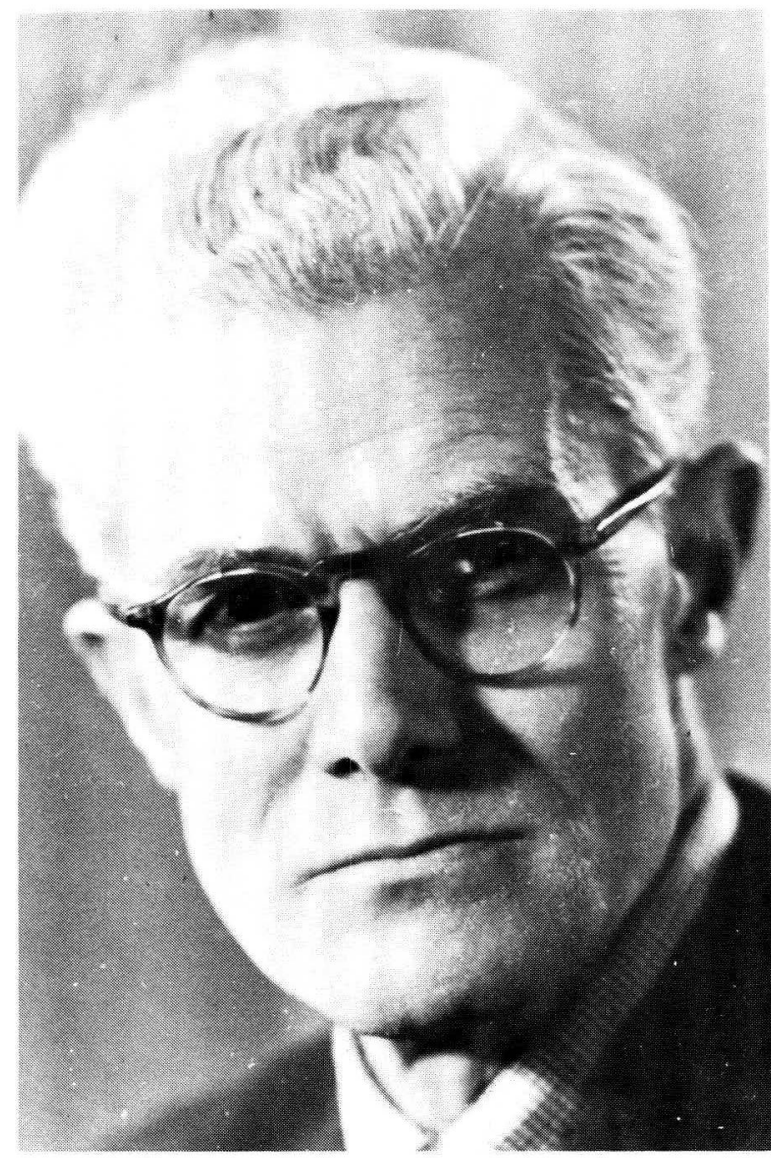

Mr H. J. R. Rieder. 


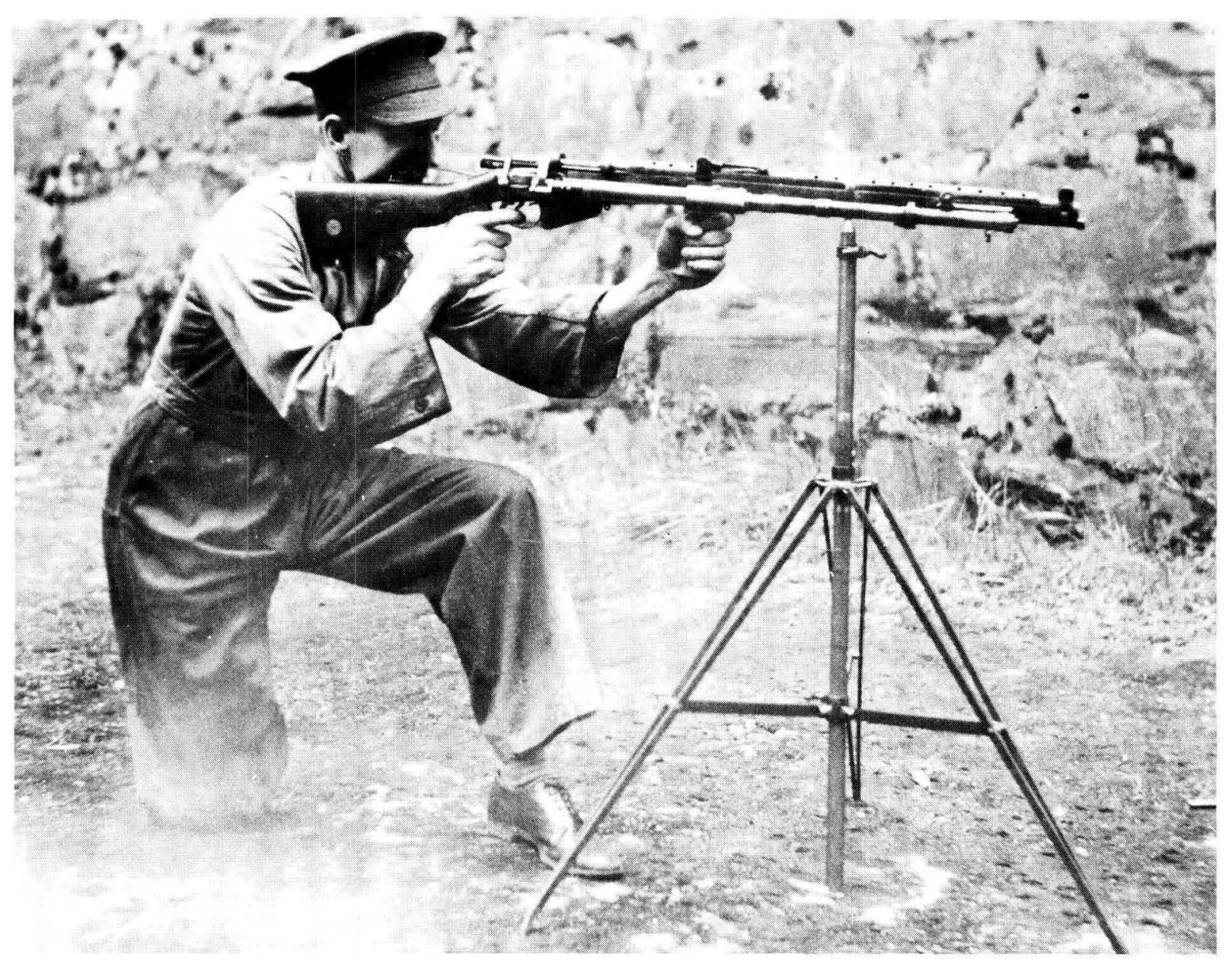

British .303 SMLE Rifles No 1 Mark III fitted with the Rieder Automatic Rifle Attachment and mounted on tripods.

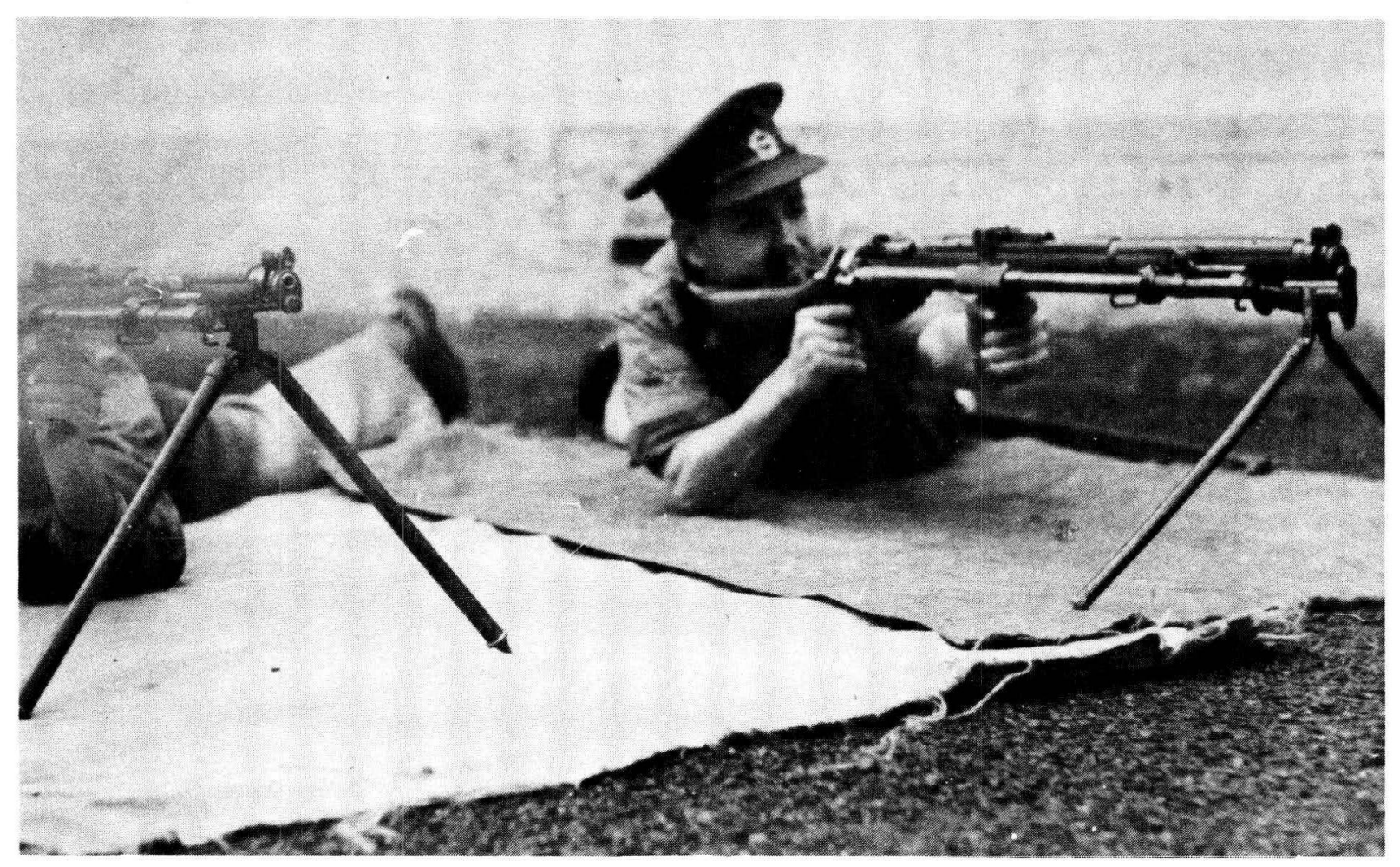


the Rieder Automatic Rifle Attachment and photographs of the invention were forwarded to the Senior Naval Officer, Simonstown on 2 January 1941 and to the Director-General of War Supplies, Dr H. J. van der Bijl, the following day.

A letter from the only cameraman permitted to be present, mentions that separate demonstrations for the Admiralty and Director-General of War Supplies were arranged. Fortunately, the African Film Productions cameraman, whose name is not recorded, has included the familiar stone walls of the Castle in some of the photographs of the demonstrations. The cameraman advised his General Manager on 14 January 1941 that permission for him to photograph the rifle had only been granted on condition that the company work through a Mr Wilson who was responsible for the arrangements concerning the release of the story. However, a telegram from DEOPS Pretoria to DECHIEF Cape Town dated 22 January 1941 stated that the negatives of films of the invention were being returned at once, care of Capt Stodel and that neither copies nor negatives had been made.

Mr Rieder's automatic rifle attachment made it possible for the ordinary service .303 rifle to operate as an automatic weapon by using the gas or pressure generated by the fired cartridge. Mr Rieder considered that the merits of the rifle attachment were its lightness (approximately $2 \frac{1}{2}$ lbs), simple construction and fitting, relative freedom from stoppages, low production costs and ease of loading. The attachment did not prevent the rifle from being used as an ordinary rifle and 'single shots could be fired with automatic loading'.

The only disadvantage listed by Mr Rieder was overheating after about 100 rounds had been fired but this he expected to overcome. In a letter to the Director-General of War Supplies, Director-General of Technical Services and $\mathrm{Mr}$ Rieder dated 31 January 1941, the Officer Commanding the Technical Services Workshops at the New Drill Hall, Maj E. P. Edwards, wrote that during demonstrations the extractor and loading springs had caused problems because they were made from piano wire which did not retain the correct length and weight. 'This problem and an incorrectly designed check spring were overcome in a new model of the attachment. Maj Edwards considered that this invention might be as free from defects as the ordinary machine gun'. Another advantage was that scarcely any oil was required and although it had a dust cover it stood up well to field conditions.

Under the heading 'remarks' Maj Edwards suggested that the eye-guard could be used for fitting an adjustable aperture sight to offset the possible difficulty of aligning the service sight caused by the rapid vibration of the rifle. Single shots could be fired by releasing the trigger quickly or alternatively the rifle could be brought to service conditions by closing the gas vent.

Although Maj Edwards wrote that it was essential that a type of elongated ring foresight be fitted, he pointed out that the introduction of tracer bullets (1 in 3) and using the hose pipe method would be useless because of the speed of modern enemy aircraft upon which the .303 bullet had 'very little effect other than the moral aspect'. ${ }^{5}$

In a letter to OC Technical Services dated 16 June $1941 \mathrm{Mr}$ Rieder requested a further extension of his temporary transfer to the Defence Department because it had proved impossible to obtain a suitable type of steel spring in the Union and this and other small improvements had impeded progress. Nonetheless, he hoped that 'perfection would be accomplished in the near future'.

On 18 June $1941 \mathrm{Mr}$ Rieder advised the Officer Commanding Technical Services Workshops in writing that his experiments had reached finality and that it would now be possible to complete the remaining sixteen rifles for demonstration purposes. He requested a further period of about six weeks to complete the task.

On 10 October $1944 \mathrm{Cdr}$ H. S. Gracie, RN presented $\mathrm{Mr}$ Rieder with the first .303 rifle (Number M-45374) to be fitted with the Rieder Automatic Rifle Attachment on behalf of the Admiralty. ${ }^{6}$

Although three rifles fitted with Mr Rieder's invention were sent overseas, it was never adopted. ${ }^{7}$ Nonetheless, Mr Rieder's ingenuity and industry in one of the darkest hours of the Second World War, deserve the highest praise. Mrs Rieder's gift, now displayed near the scene of the two demonstrations outside the Castle and the documents and photographs relating to it, have also helped fill another gap in the history of our most important national monument. 


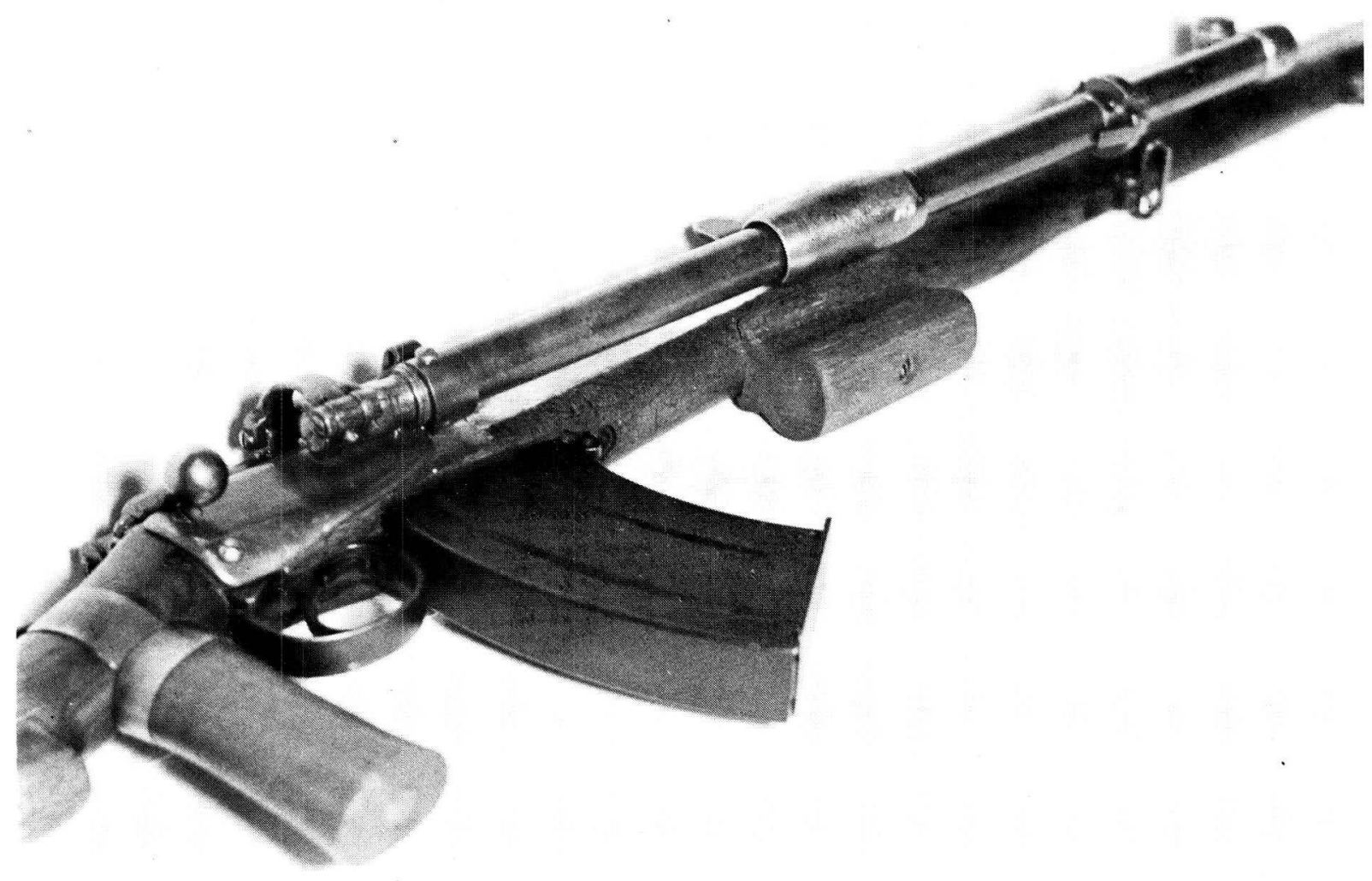

A .303 rifle fitted with the Rieder Automatic Rifle

Attachment, extra handles and a larger magazine.

The Rieder Automatic Rifle Attachment dismantled.

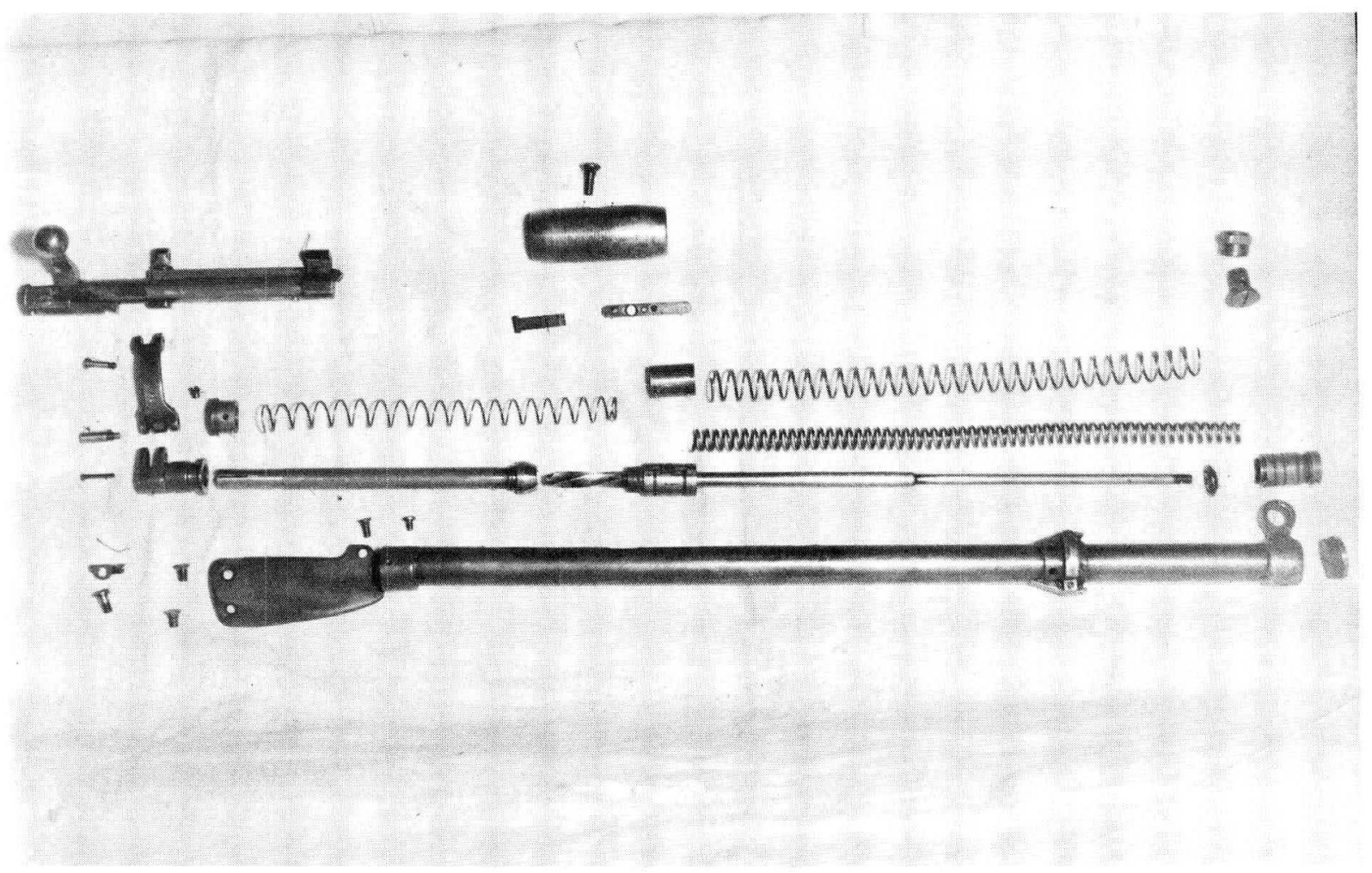


.303 Rifles fitted with the Rieder Automatic Rifle Attachment

\section{Number}

M-45374

\section{Remarks}

Obtained by Mr Rieder. Presented

to Mr Rieder by the Admiralty on 10

October 1944. Now in the Military

Museum The Castle.

Eighteen rifles received from SSOT

B92462

Z39133

F59817

G47054

B92868

N8109

Z36139

S48250

F53065

F68561

$\mathrm{H} 43785$

F45222

$\mathrm{H} 86891$

Z50675

Listed as being 'partly converted to original plan and now at Cape Town' on 20 September 1941.

\section{Rifles sent overseas}

8134

F26776

F59724

Converted to original plan

Converted to new plan 25.8.41

'Bertha'. (Taken to Pretoria by

McClelland on date not recorded).

*Lt Cdr W. M. Bisset is SO Military Musea, WP Command
Rifles completed and converted to new plan now at Cape Town

'Susie'. (Taken to Pretoria by McClelland).

Sent to Pretoria

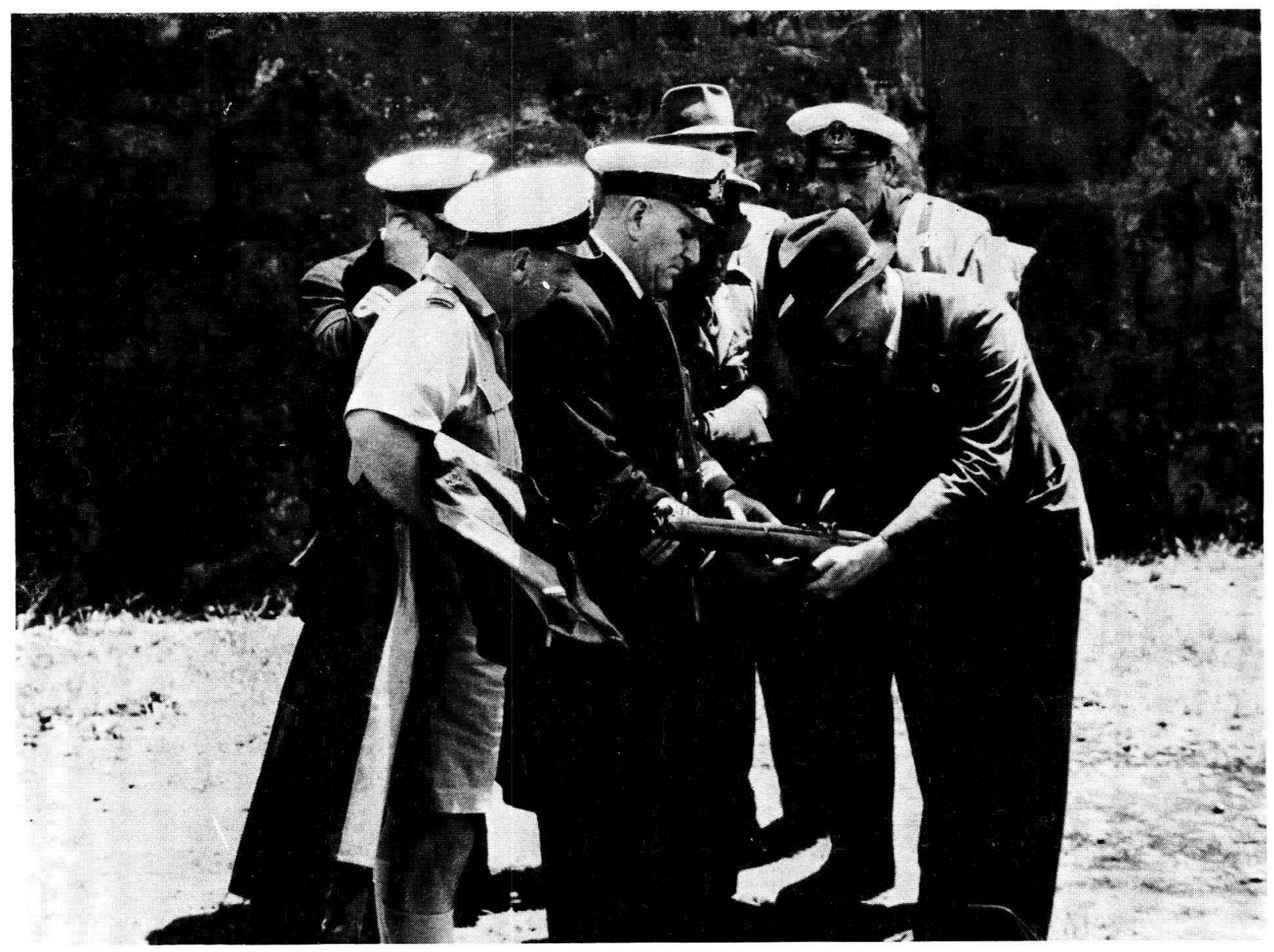

Mr Rieder shows his invention to Royal Naval officers, an army officer and a civilian after a demonstration outside the Castle in Cape Town.

\section{Endnotes}

(1) Letter from Mr Rieder to OC Cape Command dated 22 July 1940

Information provided by Mr P. D. Rieder and obituary in The Cape Times 23 November 1954

(3) Information provided by Mr P. D. Rieder.

(4) Ibid.

(5) Letter TSW 840/1 dated 31 January 1941

(6) Letter from Cdr H. S. Gracie (Office of Commander-in-Chief, South Atlantic) dated 10 October 1944

(7) Letter TSW 840/1 dated 20 September 1941 